\title{
Towards rockfall forecasting through observing deformations and listening to microseismic emissions
}

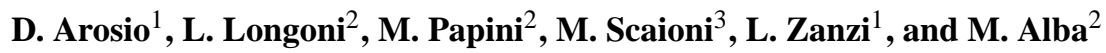 \\ ${ }^{1}$ Dipartimento di Ingegneria Strutturale, Politecnico di Milano, Piazza L. da Vinci 32, 20133 Milano, Italy \\ ${ }^{2}$ Dipartimento di Ingegneria Idraulica, Ambientale, Infrastrutture Viarie, Rilevamento, Politecnico di Milano, \\ Piazza L. da Vinci 32, 20133 Milano, Italy \\ ${ }^{3}$ Dipartimento di Scienza e Tecnologie dell' Ambiente Costruito, Politecnico di Milano, Via Bonardi 3, 20133 Milano, Italy
}

Received: 1 February 2009 - Revised: 18 April 2009 - Accepted: 4 May 2009 - Published: 15 July 2009

\begin{abstract}
Reliable forecasting of rockfall is a challenging task, mainly because of the lack of clearly noticeable forerunners as well as due to the geological and geo-mechanical complexity of the rock movements involved. Conventional investigation devices still present some drawbacks, since most measurements are generally carried out at isolated locations as well as on the surface only. Novel remote-sensing monitoring instruments, such as Terrestrial Laser Scanning (TLS) and Ground-Based Interferometric Synthetic Aperture Radars (GB-InSAR), are capable of inspecting an unstable slope with a high spatial and temporal frequency. But they still rely on measurements of the failure surface, from which displacement or velocity are measured. On the contrary, acoustic emission/microseismic monitoring may provide a deeper insight of stress and strain conditions within the subsurface rock mass. In fact, the capability to detect microseismic events originating within an unstable rock mass is a key element in locating growing cracks and, as a consequence, in understanding the slide kinematics and triggering mechanisms of future collapses. Thus, a monitoring approach based on the combination of classical methodologies, remote sensing techniques and microseismic investigations would be a promising research field. In the present paper we discuss the technologies and we illustrate some experiments conducted in the framework of a project whose final goal is the installation of an integrated monitoring and alerting system on a rockface nearby Lecco (Italy). In particular, we present a review of performances and applications of remote sensing devices and some results concerning a terrestrial laser scanner preliminary campaign. Then, we report findings regard-
\end{abstract}

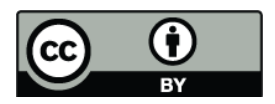

Correspondence to: L. Longoni

(laura.longoni@polimi.it) ing amplitude, frequency content and rate of signals recorded during an in situ test carried out to evaluate the performance of three different microseismic transducers.

\section{Introduction}

Monitoring of rock slopes is an essential tool in rockfall forecasting. With an effective monitoring system the kinematic aspect of mass movements can be identified in the whole investigated area.

With the final purpose of improving existing monitoring systems, we focus on the capability of recognizing crack propagation inside rock mass. With traditional methods fracture propagation can only be identified on the slope surface. The warning system based on this surface knowledge leads to an unsuitable prediction for two reasons. Firstly, surface displacements may generate false alarms because this substantial movement could not conclude in collapse failures. Thus, while providing valuable information on structural changes in the rock mass, displacement monitoring appears to have limited value in providing an indicator of collapse onset (Szwedzicki, 2003). Secondly, in other real cases, displacements measured on surface do not allow real time warning signs to be generated because when crack displacements are recorded on surface, the rock mass has often already lost bearing capacity for rock mass fracturation.

In literature, successful prediction examples of the time of failure using surface data were performed for large rock slides (Crosta and Agliardi, 2003; Rose and Hungr, 2007). Such forecasting approach can be used for large slides dominated by ductile failure but, as stated by the same authors (Rose and Hungr, 2007), the method cannot be used for small rockfalls typically dominated by brittle failure.

Published by Copernicus Publications on behalf of the European Geosciences Union. 
Nowadays the use of conventional instruments and new generation technologies provide a detailed characterization of surface rock mass in terms of assessment and monitoring, but neglecting sub-surface conditions. There are various monitoring devices that can measure the movement of the rock face. On the contrary an improvement in terms of monitoring within the rock mass is still needed. To pursue this scope an advance in "listening to the rock mass" is required for a comprehensive knowledge of crack propagation within the rock mass itself.

Slope monitoring systems should be designed considering adequate geological and geomorphological information; in fact, they require a detailed 3-D model of the fracture network with minimum uncertainty of geological and structural conditions. The physical model of the slope allows slope behavior to be defined and the most suitable monitoring approach to be identified. Actually, the monitoring system can be defined only with considerable knowledge of plausible hydrogeological scenarios, available only when there is a detailed conceptual model. The geological assessment shows a physical model in three dimensions through the use of surface and sub-surface investigations (Arosio et al., 2009). The processing of the collected monitoring datasets should generate a dynamic model that reveals the evolution of the physical model. Considering the high spatial and temporal variability of complex hydrogeological scenarios, the combination of surface and sub-surface monitoring systems appears to be an interesting way to go, in order to develop monitoring strategies able to effectively address rockfall forecasting.

After a short preface concerning conventional and recent surface monitoring methods (Sect. 2), terrestrial remote sensing techniques and results of some tests (Sect. 3) are presented in this paper. Section 4 describes the potential and critical issues of subsurface monitoring through passive microseismics. A field test, supported by laboratory analysis, is also illustrated to discuss the properties of acoustic emissions generated by crack propagation within the rock mass. Finally, in Sect. 5 some conclusions are drawn and expected future developments portrayed.

\section{Conventional monitoring devices}

These monitoring systems include all techniques and/or tools for the direct measurement of the spatial and/or temporal evolution of risk scenario processes.

What type of monitoring instruments depends on the hydro-geological problem to be evaluated. For the best results in drawing the evolution of the physical model, the technologies employed should be chosen after a preliminary analysis, so that the final purpose of the system can be clarified.

Crack propagation is one important indicator in predicting rockfall. Cracks can occur along discontinuities that act on rock bridge or around karst areas and sometimes, but rarely, in intact rock.
The problem can be split in two parts: the first regards fracture measurement on rock face (i) and the second regards crack detection within rock body (ii).

Geotechnical instrumentation allows the rock mass behavior to be analyzed taking changes in terms of displacement and stress into account. Displacement measures are commonly used for slope stability problems and an excellent and thorough description of monitoring tools can be found in Szwedzicki (2003). Some instruments used for crack propagations on a rock mass surface (e.g., crack meters, surface extensometers, joint meters) do have some drawbacks: firstly, they may allow only a few critical points on an entire rock face to be assessed; secondly, they cannot evaluate subsurface discontinuities within the rock mass; and finally, they generally do not make timely alarm activation possible. According to Sullivan (1993) the monitoring of only few critical points or lines leads to a harsh interpretation of failure mechanisms. The definition of effective thresholds is therefore practically impossible when using such measuring devices. Among geotechnical monitoring systems the sub-surface instrumentations (e.g. inclinometers, TDR, wire extensometers) are not considered because these techniques are generally considered best suited for other kind of landslides (see e.g. Crosta and Agliardi, 2003).

Recently developed technologies are used nowadays to address problems of stability in civil engineering: Total Stations (TS), Terrestrial Laser Scanning (TLS) and Ground-Based Interferometric Synthetic Aperture Radar (GB-InSAR) monitoring. These techniques will be described in Sect. 3. The use of other remote techniques like Global Navigation Satellite Systems (GNSS; Hofmann-Wellenhof et al., 2008) and satellite-based InSAR processing (Ferretti et al., 2001) is widely adopted for ground slopes, but it is not suitable for rock faces, because they require an open visibility of the sky. From the geotechnical point of view, these methodologies have the advantage of being able to monitor extended areas and volumes and not only points as in the case of extensometer and joint (crack) meters. Moreover this equipment allows data to be monitored in real time, which is an important advance in rockfall forecasting.

Unfortunately, crack propagation inside rock mass is not monitored by any of these instruments. As underlined above, for a complete view of rock mass condition and evolution it is essential to look inside the rock mass. While for the assessment of a rock slope, Ground Penetrating Radar (GPR) sounding can be usefully applied, for crack propagation monitoring, new instruments have to be considered (Sect. 4).

\section{Terrestrial remote sensors}

This term includes all monitoring techniques that are capable of remotely measuring geometric changes, displacements or deformations of a rock slope surface. The instruments that will be discussed here are: Total Stations (TS), Terrestrial 


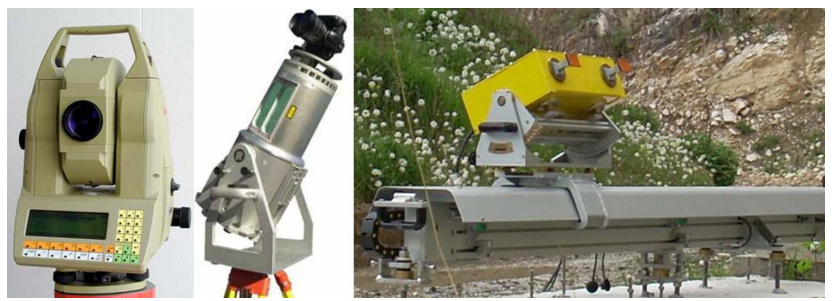

Fig. 1. From left to right, examples of up-to-date TS (Leica TCRA2003), TLS (Riegl LMS-Z420i), and GB-InSAR (IDS IBIS-L) sensors.

Laser Scanners (TLS), Ground-Based Interferometric SAR sensors (GB-InSAR); in Fig. 1 some examples of these instruments are reported.

Some experimentation involving the use of TS and TLS were carried out in the test-site named A located on the same area in the Italian Pre-Alps of test-site named B presented in Sect. 4.3. Both sites feature similar geological and geomorphological characteristics.

\subsection{Total stations}

Total stations can measure the 3-D coordinates of a point through direct readings of horizontal and vertical angles, combined with a range-finder for the measurement of distances. This can work on the basis of two different techniques: the first one is based on the "phase-shift" evaluation of electromagnetic carrier wave returns and requires a reflector on the point to be measured; the second is based on the measurement of the Time-of-Flight (ToF) of a pulsed-laser signal, with the advantage of operating without reflectors, albeit with a minor precision. Modern total stations are usually equipped with both range-finders (see Henk, 2007 for a market-survey of Tss). Further references on the main technological aspects of TSs and their operational use in geodetic networks can be found in Anderson and Mikhail (1997) and Saleh and Al-Bayari (2007). By comparing coordinates found at different epochs, components of the 3-D displacement vector of a point can be found. To achieve the best accuracy required for rockfall forecasting measurements, the points to be tracked need to be materialized with the reflectors required by "phase-shift" range-finders, which are more appropriate in the most monitoring applications because of their higher precision $( \pm 1-2 \mathrm{~mm})$ with respect to ToF instruments $( \pm 3-5 \mathrm{~mm})$. On the other hand, these instruments are more practical for applications where a less precision is required, for example in the case of the geometric modeling of a cliff (see e.g. Lambrou and Pantazis, 2006). This fact results in a limitation of the number of control points. Upto-date TSs are also equipped with a device for automatic collimation of targets; this possibility makes readings independent from the skill of the surveyor and results in more objective comparisons. This class of instruments, also referred

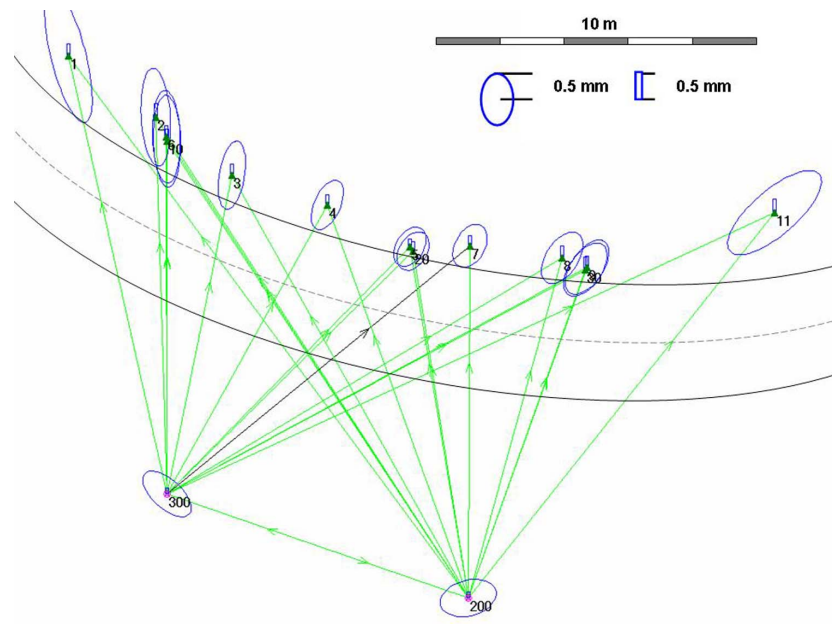

Fig. 2. Geometric layout of TS measurements on the test-field A on the SP Esino-Parlasco. Error ellipses (confidence level 95\%) are depicted to show the precision of measurements.

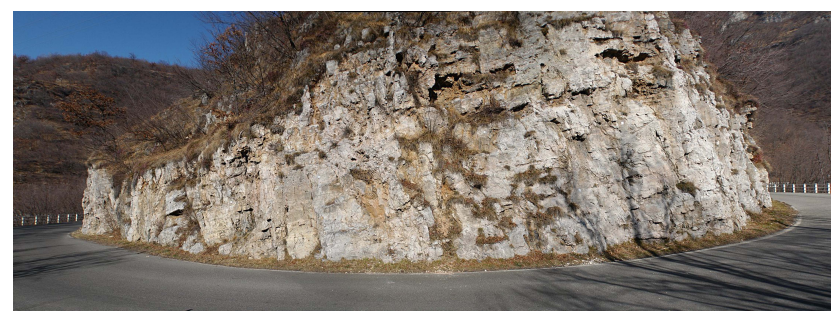

Fig. 3. Picture of the rock face chosen as test-site for testing TS and TLS measurement for monitoring purpose (test-site A).

to as "robotic TS", is equipped with engines that allow the automatic repositioning so that the same control point can be targeted at different times.

Furthermore, some innovative instruments for deformation monitoring (including rock slopes) based on the TS structure integrated by a digital camera (videotheodolites, Reiterer et al., 2008) are currently under development and testing.

In Fig. 2 the geometric scheme adopted for TS measurements on a small rockface at test-site A (Fig. 3) is reported. Here the very small distances involved $(\max 28 \mathrm{~m})$, and the intersection of measurements taken from two stations allowed 3-D point displacements to be determined with a sub-millimetre precision (see error ellipses in Fig. 2) even if retro-reflective targets were used as reflectors instead of high-precision prisms. Conversely, the number of points controlled is limited (13), and only global slope deformations or the stability of the biggest rock blocks can be assessed. Measurements were taken in 3 moments of a 4-month period. No significant displacements were detected, neither at the global nor at the local level. 


\subsection{Terrestrial laser scanners}

Terrestrial laser scanners (Pfeifer and Lichti, 2004) can be considered an evolution of TSs that extend the measurement capability from single points up to a large set of unspecific points on a given surface. Broadly speaking, an electronic laser range-finder is quickly rotated on a horizontal and a vertical plane with respect to the instrument; during its movement, the emission of a laser beam is reflected by the surface to be measured and allows range measurements at nodes of a regular grid to be returned to the sensor. The range measurement principles are two: ToF and "phase-shift" measurement. The former allows a much longer maximum measurement range (up to $1 \mathrm{~km}$ and much more in the case of special instruments) at a lower precision $(1-2 \mathrm{~cm})$ level; the latter can be used at shorter distances (up to $50-100 \mathrm{~m}$ ) but with better precision (a few millimeters).

The application of TLS for the geometric survey of a rockface (Alba et al., 2005) is a standard practice today, but applications for automatic extraction of the geomorphological structure are being developed quickly (Roncella and Forlani, 2005; Abellán et al., 2006). This topic, which is termed rockslope assessment, is the subject of a companion paper on this volume (Arosio et al., 2009).

Potentially, the use of TLS for monitoring rockface deformation by comparing point-clouds surveyed at different times is a great challenge. Indeed, instruments like Tss give more precise measurements but are bound to a few points, while laser scanning offers information on full surfaces. On the other hand, TLS is capable of measuring unspecific points describing the surface of an object and is not aimed at specific points. This means that the comparison between multi-temporal point-clouds cannot be carried out point-wise, because there is no precise correspondence between points. Consequently, only techniques that compare entire point-clouds or that interpolate data with known surfaces can be applied to detect the deformation (Tsakiri et al., 2006). The possibility of detecting all the spatial components of point displacements is related to the geometric shape and texture of the object: only the presence of discontinuity along a given direction (like e.g. in the experience described by Gordon and Lichti, 2007; Monserrat and Crosetto, 2008) allows a displacement to be evaluated along that line. Consequently, if the object is flat, only deformation along its normal direction can be evaluated (Alba et al., 2006). Furthermore, the intrinsic precision of TLS does not make it possible to obtain measurements that can detect very small deformation on a rock, such as those preannouncing a collapse. To overcome this problem, the computation of the mean displacement inside a given area seems to be a very promising technique (Lindenberg and Pfeifer, 2005; Abellán et al., 2009), because it allows the uncertainty of possible displacements to be reduced.
Another important result that can be obtained by comparing TLS measurements at different epochs is the so called "change detection", i.e. an evaluation and localization of the amount of rock which has detached itself from the rock slope. A wide scale interesting application is reported at PermadataRoc (2009). This information is really important, because a more precise estimation of rock detachments can be used to tune the strategy for rockfall risk mitigation.

Some experiments on the application of TLS for rockface monitoring were carried out at different test-sites. The results obtained at test-site A are reported and discussed in the present paper.

Scans have been acquired by a Riegl LMS-Z420i laser scanner (Riegl, 2009), a ToF instrument with long-range capability, featuring a standard deviation of range measurement of $\pm 10 \mathrm{~mm}$ in the considered ranges. The data acquisition stages were designed in order to reduce all the error sources contributing to the whole error budget, including the use of a removable steel pillar that always constrains the laser scanner to be exactly fixed in the same position. Three degrees of freedom remain in correspondence with the rotations of each scan around the instrument's center. Different strategies to eliminate them were tried, but the best results were obtained with the use of a surface matching algorithm (ICP).

By comparing scans taken at 3 times (December 2007, February 2008, March 2008), average discrepancies between scans were $0.2 \mathrm{~mm}$ between December 2007 and February 2008, and $3.3 \mathrm{~mm}$ between December 2007 and March 2008, respectively. The standard deviations of discrepancies were both about $\pm 9 \mathrm{~mm}$, meaning the same error distribution occurred. TS measurements on control points observed at the same times revealed that no significant global deformations affected the slope. This fact agrees with the TLS results of February 2008, but not with those of March 2008. The technique adopted to compare the scans was based on the construction of a Triangulated Irregular Network (TIN) of different point clouds. Figure 4 shows the results of TLS-based change detection analysis applied to the case study in Fig. 3. Here some rocks of less than $0.5 \mathrm{dm}^{3}$ in size were detached between two measurement times, and then correctly identified by comparing both TINs.

\subsection{GB-InSAR sensors}

GB-InSAR sensors can be used to overcome the limitation in precision typical of TLS. These are the implementation with terrestrial remote sensing of a technique that has been successfully applied on satellite and airborne sensors (Ferretti et al., 2007). Even though the interferometric radar technique and its implementations are really complex from a theoretical point of view (Stimson, 1998), the operational principle is quite simple. A radar antenna emits a microwave wavefront oriented towards the object to be measured, which is reflected towards a receiver antenna and recorded. The interferometric technique is used to track relative deformations of the surface 


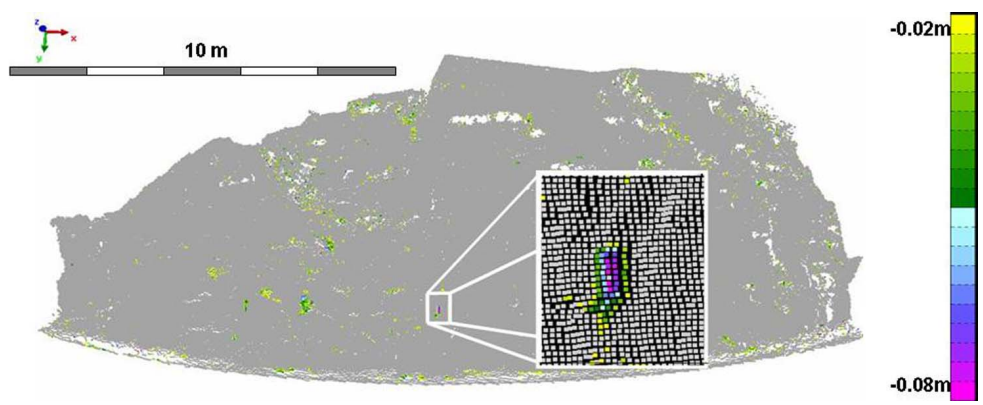

Fig. 4. Areas where changes have been detected by comparing more scans taken by a TLS Riegl LMS-Z420i in test-site A. Red zones correspond to small rocks detached which have been found at the bottom of the rock face (see sub-picture).

along range direction over a given period of time. This solution requires the permanent positioning of the radar during the whole observation period, or alternatively a very accurate repositioning. To carry out this task a Digital Surface Model (DSM) of the site is usually needed and this can be provided by TLS (Lingua et al., 2008). The second problem is related to "range resolution". As shown in Fig. 5, each radar sensor has a given angular Field-of-View (FoV), depending on the geometric shape of the antenna. The space in front of it is divided into range-resolution spherical sectors, each of them returning one echo to the radar. This means that for each range resolution sector only one displacement in range can be measured. If a point with higher scattering properties with respect to the remaining surface is present in a sector (for example a natural or artificial "corner reflector"), its displacement will be tracked. Otherwise, the measured relative displacement will arise from the contribution of many returns, without a physical meaning. The application of this kind of sensor for rock slope monitoring is not possible due to the difficulty of finding predominant natural scatterers.

To improve spatial resolution, the Interferometric Synthetic Aperture Radar (InSAR) technique was implemented in terrestrial sensors as well. The radar sensor is moved along a track, so that the space in front of it is divided into many angular resolution cells. The combination of angular and space resolutions gives out many smaller areas; the red pixel in Fig. 5 is the planar projection of a resulting resolution cell. Inside each cell, the best scatter point can be tracked. Then, the intersection of the target object surface with the resolution cells defines how many points can be tracked by the GBInSAR system. In the case of a slope with limited inclination (up to $60^{\circ}$ ), the surface can be split into many resolution cells in order to track points with millimeter accuracy, that in such cases is enough for predict landslides (Leva et al., 2003; Tarchi et al., 2003; Corsini et al., 2006). The possibility of monitoring rock faces is open (Antonello et al., 2004), considering also results obtained in other similar structures, for example large dams, where in different applications a large number of point displacements were observed and validated with an accuracy under $\pm 1 \mathrm{~mm}$; (Tarchi et al., 1999; Alba et

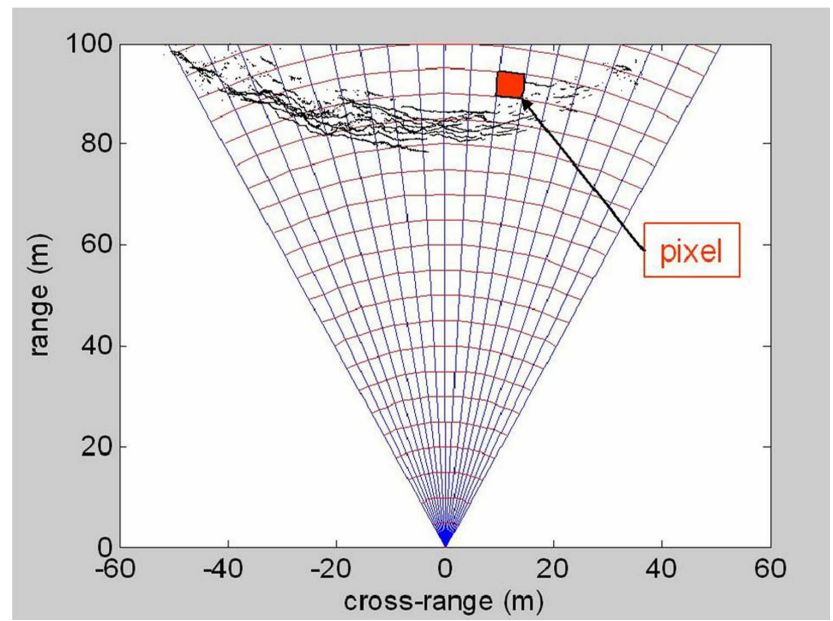

Fig. 5. Figure depicting the geometric resolution of different radar techniques. Concentric circles indicates the "range-resolution", while angular sectors the "cross-range resolution" obtained from the use of SAR technique.

al., 2008). Furthermore, GB-InSAR in which the radar head can be moved along two orthogonal directions allows the definition of a finer grid of angular resolution cells (Werner et al., 2008). This can be really useful in case of vertical or sub-vertical rock faces.

\section{Microseismic monitoring}

\subsection{Principle and applications}

Acoustic Emission/Microseismic (AE/MS) activity originates as an elastic stress wave at locations where the material is mechanically unstable. The AE/MS technique has been studied for over sixty years and it is routinely used today in a wide range of applications.

Originally, research was focused in particular on rock burst and roof fall prediction in mines (Obert and Duvall, 1942). Then many efforts were specifically oriented to the 


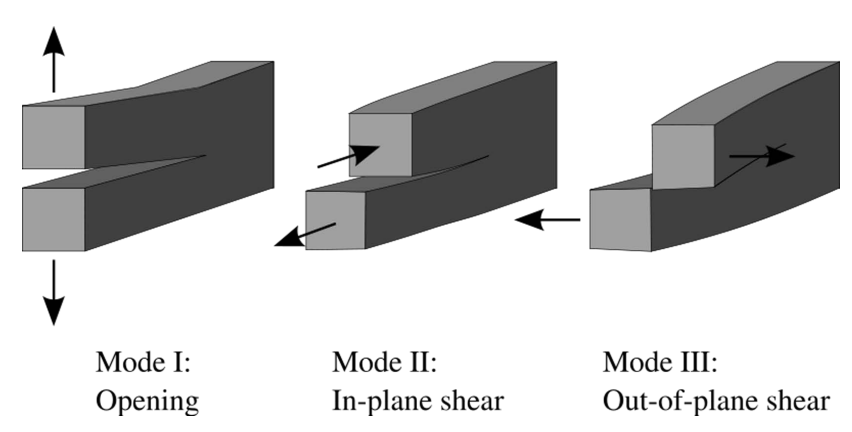

Fig. 6. Modes of fracturing.

development of AE/MS techniques in the general area of geotechnical engineering (Hardy, 2003). In recent years the application of AE/MS monitoring has rapidly increased and, at present, such techniques are mainly employed for stability assessments in underground structures such as mines and tunnels, the evaluation of hydrofracturing processes within natural gas, oil as well as geothermal reservoirs, the investigation of massive structures (e.g., foundations, bridge piers, dams) and, finally, the monitoring of unstable slopes and cliffs (Spillmann et al., 2007). As far as slope stability is concerned, microseismic investigation is usually employed as part of an integrated approach (Green et al., 2006; Spillmann, 2007), involving, besides conventional geological mapping and geodetic measurements, other specific geophysical methods such as surface and borehole ground penetrating radar, seismic tomography as well as seismic refraction surveying, and ground (or satellite)-based radar interferometry. Though microseismicity studies themselves can hardly provide a comprehensive knowledge of the instability affecting a slope, they could help develop a site history in terms of changes in microseismic activity as well as of collected waveform characteristics over time. Eventually, data recorded with an efficient microseismic network could be merged with datasets from other investigations in order to develop a predictive capability based on the kinematic and dynamic behavior of the mountain slope (Danish et al., 2008).

\subsection{Crack propagation theory}

An understanding of crack evolution is necessary to recognize pre-failure rock mass behavior. Figure 6 reports the three different fracturing modes that can usually occur (Griffith, 1920; Zhang, 2002). In mode I, tensile form, displacements are perpendicular to the crack plane, therefore crack propagation is on the fracture plane. On the contrary, mode II and mode III are characterized by shear strength.

Lab analysis on rock samples confirmed a good correlation between AE rate and inelastic strain rate (Lockner, 1995) and this suggests that collected AE data may play a fundamental role in defining useful thresholds for describing the rock slope evolution trend. A typical diagram of a rock sample is presented in Fig. 7 and shows the stages of crack development according to stress, strain and AE event count. The failure process can be split up into five successive phases featuring different stress-strain traits as shown by the axial and lateral deformation measurements recorded during laboratory tests. These phases were defined as 1- crack closure, 2linear elastic deformation, 3- crack initiation and stable crack growth, 4- critical energy release and unstable crack growth and finally 5- failure and post peak behaviour (Eberhardt et al., 1998).

Moving from laboratory analysis, Cai et al. (2004) have proposed generalized crack initiation and damage stress thresholds for rock slopes in terms of soliciting stresses and rock mass strength

$\sigma_{1}-\sigma_{3}=A \cdot \sigma_{\mathrm{cm}}$

$\sigma_{1}-\sigma_{3}=B \cdot \sigma_{\mathrm{cm}}$

where $\sigma_{1}$ and $\sigma_{3}$ represent respectively the maximum and the minimum principal stress, $A$ and $B$ are constants and $\sigma_{\mathrm{cm}}$ is the uniaxial compressive strength of rock mass. The generalization was carried out combining rock mass quality assessment techniques, direct visual analysis and AE/MS monitoring.

The relationship between monitoring data and crack propagation through threshold identification is an important achievement for alarm generation.

Natural rock fractures are predominantly associated with mode I crack propagation (Atkinson, 1991) and in Alpine areas vertical joints subjected to triggering factors (e.g., crioclastism) show this tensile fracturing. Crack propagations along discontinuities generate rupture processes inside the rock mass acting on rock bridges. In jointed rock mass the presence of rock bridges plays an important role in the study of rockfalls. Therefore knowledge of fracture persistence is essential to predicting rock slope movements.

\subsection{Experimental test}

The typical sequence of events before a burst is an increase in microseismic activity in a given volume of rock, followed by a decrease, and then the burst. It has also been observed that events are likely to have more energy and lower frequency content when approaching a failure. If this assertion is true, then it is clear how important it is to design an efficient monitoring network with suitable transducers able to detect microseismic events without altering their energy and frequency characteristics. Following initial laboratory analysis (Alippi et al., 2007), we performed a field test with the intention of correlating forced propagation of an existing fracture with the features of the signals collected. Electromagnetic velocimeters (geophones), piezoelectric accelerometers and sensors based on MicroElectric-Mechanical-System (MEMS) technology were employed and compared to explore their capability of revealing microseismic emissions in real propagation conditions. 


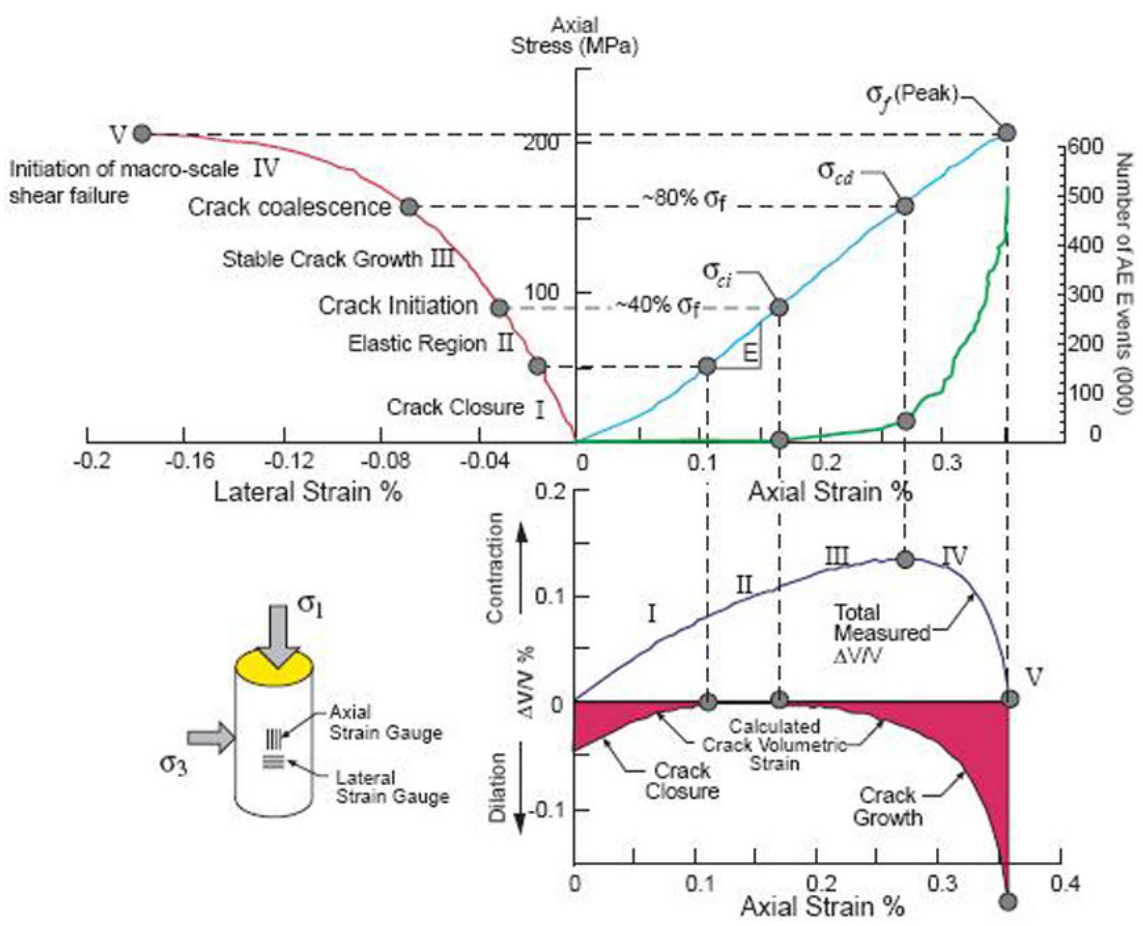

Fig. 7. Stress-strain diagram. Typical stress versus strain plot for hard rock (after Martin et al., 2001).

Test-site B (Fig. 8) is located in the Pre-Alpine region (provincial road SP65 between the villages of Esino and Parlasco in the Province of Lecco, Northern Italy). In this area metalliferous limestone outcrops without any marl interbed, and it is generally neither much altered nor fractured. A small rock face (a few hundred square meters) along a country road was selected as a convenient test location because of its accessibility and the possibility of operating safely.

In this area the stability of rock cliffs is controlled by subvertical discontinuities. Crioclastism processes and water pressure are, for example, triggering factors for these instabilities affecting the existing fracture network. These factors can generate crack propagations mainly along vertical fracture planes, as stated above. Microseismic monitoring experiments were performed to monitor AE due to crack propagation on a cliff near test-site A that was also selected as the target of a geological assessment trial (Arosio et al., 2009). As reported in crack propagation theory, mode I is the most common fracture type.

Although, relating to hazard evaluation, the most interesting fracture for stability problems is the vertical joint set parallel to the cutslope plane, the monitoring test was performed on a shallow vertical fracture perpendicular to topography.

Five vertical geophones were deployed on the rock face according to the sketch depicted in Fig. 8; a MEMS accelerometer as well as a piezoelectric accelerometer were glued to the rock surface in correspondence with a geophone in order to collect datasets useful for comparison. The direction from the source to the sensors was almost perpendicular to
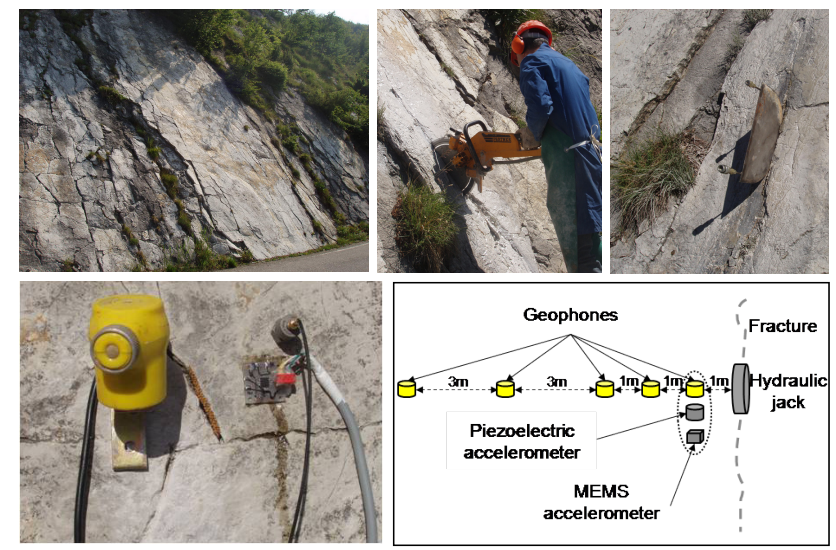

Fig. 8. Test site B and deployment of hydraulic jack and sensors.

the sensor axes; therefore, shear-wave excitation should be a more significant part of the sensor outputs. Details concerning acquisition parameters and hardware are listed in Table 1. Note that the associated acquisition system imposed a low geophone sampling frequency.

Geophones are relatively low-cost, passive, electromagnetic velocimeters characterized by a flat response above their natural frequency and are being used extensively in the oil industry for hydrocarbon exploration. On the other hand, accelerometric sensors work under their resonance frequency and typically need some sensing circuitry to deliver 
Table 1. Features of the sensors and acquisition parameters.

\begin{tabular}{lrrrrrrr}
\hline Instrument & Sensitivity & $\begin{array}{r}\text { Natural } \\
\text { frequency }\end{array}$ & Bandwidth & $\begin{array}{r}\text { Sampling } \\
\text { frequency }\end{array}$ & ADC & $\begin{array}{r}\text { Volt } \\
\text { range }\end{array}$ & Gain \\
\hline $\begin{array}{l}\text { Geophone } \\
\begin{array}{l}\text { Piezoelectric } \\
\text { accelerometer }\end{array}\end{array}$ & $0.32 \mathrm{~V} / \mathrm{cm} / \mathrm{sec}$ & $8 \mathrm{~Hz}$ & $8-? \mathrm{~Hz}$ & $1-4 \mathrm{kHz}$ & $24 \mathrm{bit}$ & $2.8 \mathrm{~V}$ & $24 \mathrm{~dB}$ \\
$\begin{array}{l}\text { MEMS } \\
\text { accelerometer }\end{array}$ & $9.8 \mathrm{pClg}$ & $42 \mathrm{kHz}$ & $0.01-12600 \mathrm{~Hz}$ & $10 \mathrm{kHz}$ & $12 \mathrm{bit}$ & $\pm 10 \mathrm{~V}$ & - \\
\hline
\end{tabular}

Table 2. Accumulated microseismic activity along the recording session.

\begin{tabular}{crrr}
\hline $\begin{array}{c}\text { Recording } \\
\text { number }\end{array}$ & Mems & Piezo & Geophone \\
\hline 1 & 1 & 0 & 13 \\
2 & 0 & 0 & 9 \\
3 & 1 & 11 & 36 \\
4 & 1 & 20 & 32 \\
5 & 4 & 28 & 18 \\
6 & 3 & 8 & 179 \\
\hline
\end{tabular}

meaningful data (though piezoelectric devices are intrinsically passive). But, while piezoelectric systems are very high-priced, MEMS accelerometers are incredibly inexpensive as well as tiny and are thus promising for the implementation of monitoring networks with a large number of units in harsh mountain environments. However, their development is still in its infancy and drawbacks such as low sensitivity, limited bandwidth and high power consumption need to be tackled.

Six consecutive acquisition tests were performed while emissions were induced by soliciting cracks with a hydraulic jack installed in a pre-existing superficial fracture, previously adapted with the help of a grinding wheel (Fig. 8). Signals from accelerometers were affected by very low frequency oscillations $(0.1-0.2 \mathrm{~Hz})$, probably due to the sail effect caused by trees at the top of the rock face. Computation of RootMean-Square (RMS) background noise values revealed that the geophone definitely shows the best performance, being in actual fact the only passive device.

In a qualitative inspection of the datasets, it was assumed that the stress generated by the expanding hydraulic jack caused only weak emissions at first, because of the low fluid pressure. From the third recording on, stronger signals were collected at an increasing rate which is indicative of the breaking process of the rock bridges between the isolated block and the rock face. Finally, during the last recording, fluid pressure in the jack reached 25 bar and the strongest signal, associated with a clear audible sound, was collected. After that, microseismic activity almost ceased and slow oscillations were sensed just by the geophone. Since we were able to visually identify movements of the rock block as well as fracture propagation on the surface, we interpreted this final stage as representative of the stage just before the burst, when microseismic activity tends to decrease.

Accumulated microseismic activity, i.e. the total number of events observed during a specific period of time (Hardy, 2003), was computed for all the recordings of the acquisition session. Analysis was carried out on raw datasets and the accumulated activity counter was increased each time an event had an amplitude $6 \mathrm{~dB}$ higher than the background noise. As expected, the number of recorded events increased as the critical stability condition approached. Table 2 displays how MEMS accelerometer exhibits the lowest sensitivity. Geophone data analysis resulted in enormous event counts because of the remarkable performance of the associated acquisition chain, along with the presence of low frequency signals (especially in recordings 3, 4 and 6) that were probably due to some resonance affecting geophone mount (Rowell and Yoder, 1984).

The six most significant events were selected from the MEMS accelerometer dataset (i.e. the least sensitive device), and corresponding emissions revealed with the other transducers were analyzed as well (Fig. 9). The spectra of the accelerometers appear to be similar; obviously, the filtering effect of the MEMS transfer function significantly attenuates signals above $3 \mathrm{kHz}$. Each event shows its peculiar spectrum and the lack of specific predominant frequencies implies that no resonances are present (resonance phenomena may be the result of the location of the sensors, e.g. accelerometers mounted on a large piece of loose rock, as well as the result of a non optimal sensor mounting system).

On the other hand, the geophone has a high energy peak constantly concentrated around $120 \mathrm{~Hz}$; this is believed to be a resonance of the mounting, since it does not affect the frequency content of the accelerometric devices. Useful signals centered around $400 \mathrm{~Hz}$ are likely to be limited by the constraint imposed by a too low sampling frequency. Additionally, since the upper limit of the geophone band is not 

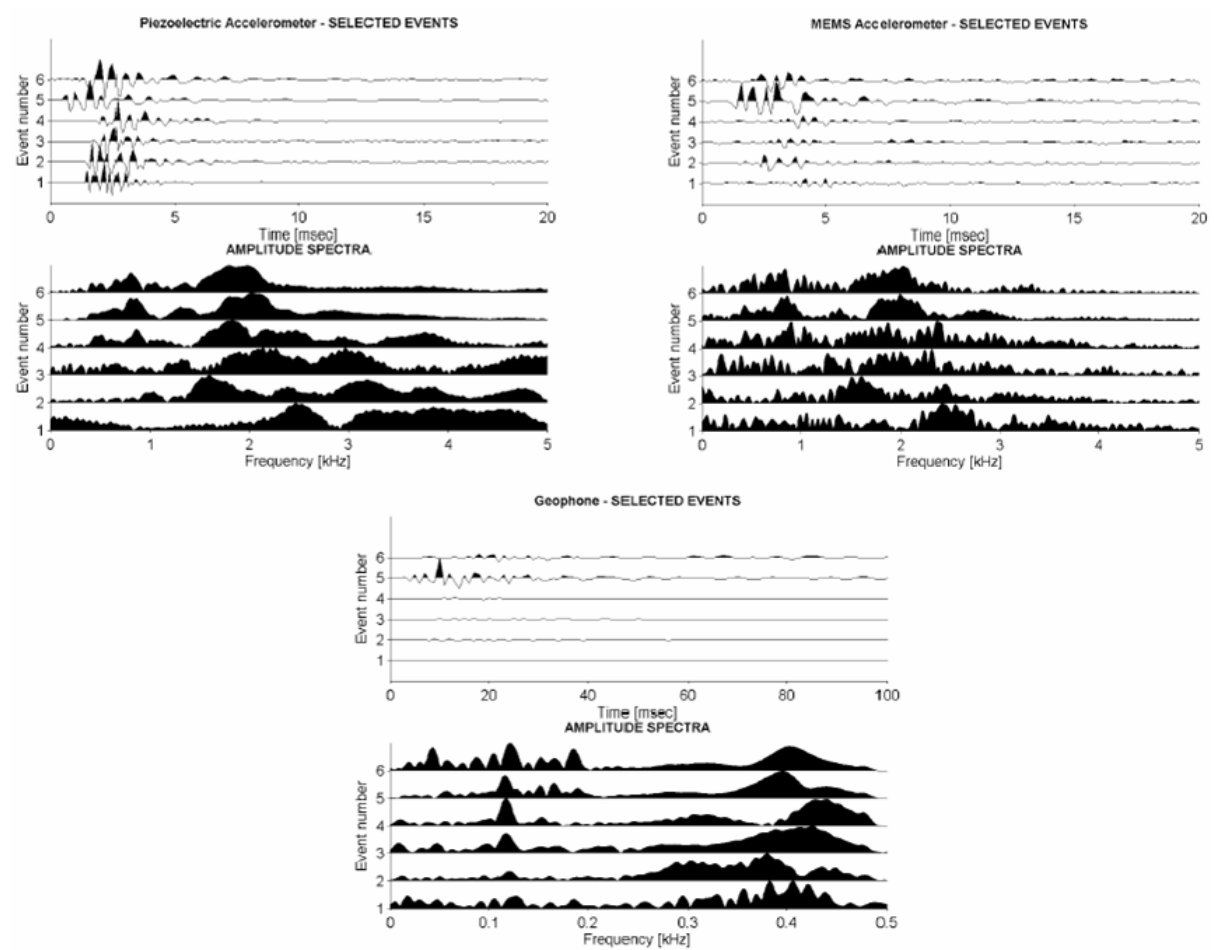

Fig. 9. Time histories and amplitude spectra of the 6 selected events as gathered by each transducer (time histories of MEMS sensor and geophone are normalized to the overall maxima, while all amplitude spectra and signals collected with the piezoelectric accelerometer are normalized to the maximum of each event).

known, attention should also be paid to the occurrence of spurious frequencies that may affect the quality of recording (Faber and Maxwell, 1997).

It is interesting to note how the frequency content of selected events shifts towards lower frequencies when the breaking process is approaching complete failure (i.e., from event 1 to event 6). As stated above, this particular behavior has already been noted before and it is remarkably clear when looking at the piezoelectric data. Signal-to-noise ratios of the events (Fig. 10) provide as well information about an increase in energy of the emissions and, once more, the piezoelectric accelerometer performs best. Despite its enormous dynamic range and its extremely low background noise, the geophone displays lower SNR values and only eventually so they become higher than the piezoelectric ones. The cause of this should most probably be sought in the limited bandwidth of the velocimeter; as a matter of fact, we found out that the strongest signals revealed by the geophone were not correspondent with the strongest signals sensed by the accelerometric devices.

The presence of a 5-geophone spread allowed the computation of amplitude attenuation along the array, as well as the evaluation of frequency decay with distance. A typical event sensed by the geophones is illustrated in Fig. 11; both time histories and amplitude spectra indicate that useful signals could be collected up to nearly $10 \mathrm{~m}$ from the source. In

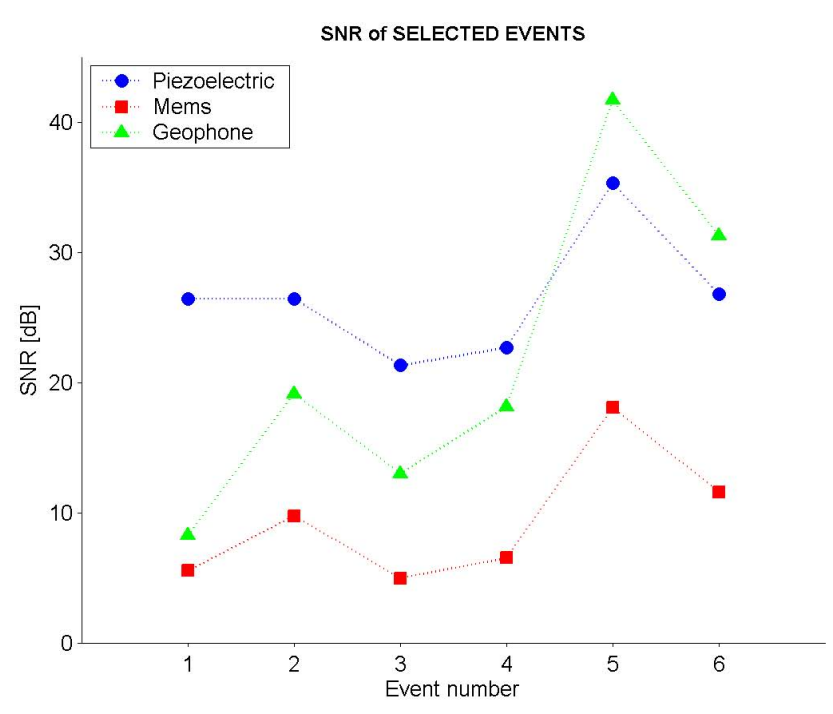

Fig. 10. Signal-to-noise ratios of the selected events.

order to perform a similar analysis with the accelerometric transducers (but with only one sensor), a hammer was used to hit the rock surface and generate vibrations at an increasing distance from the sensors. A distance range from $1 \mathrm{~m}$ to $10 \mathrm{~m}$ was explored and, even though the shot generated by 

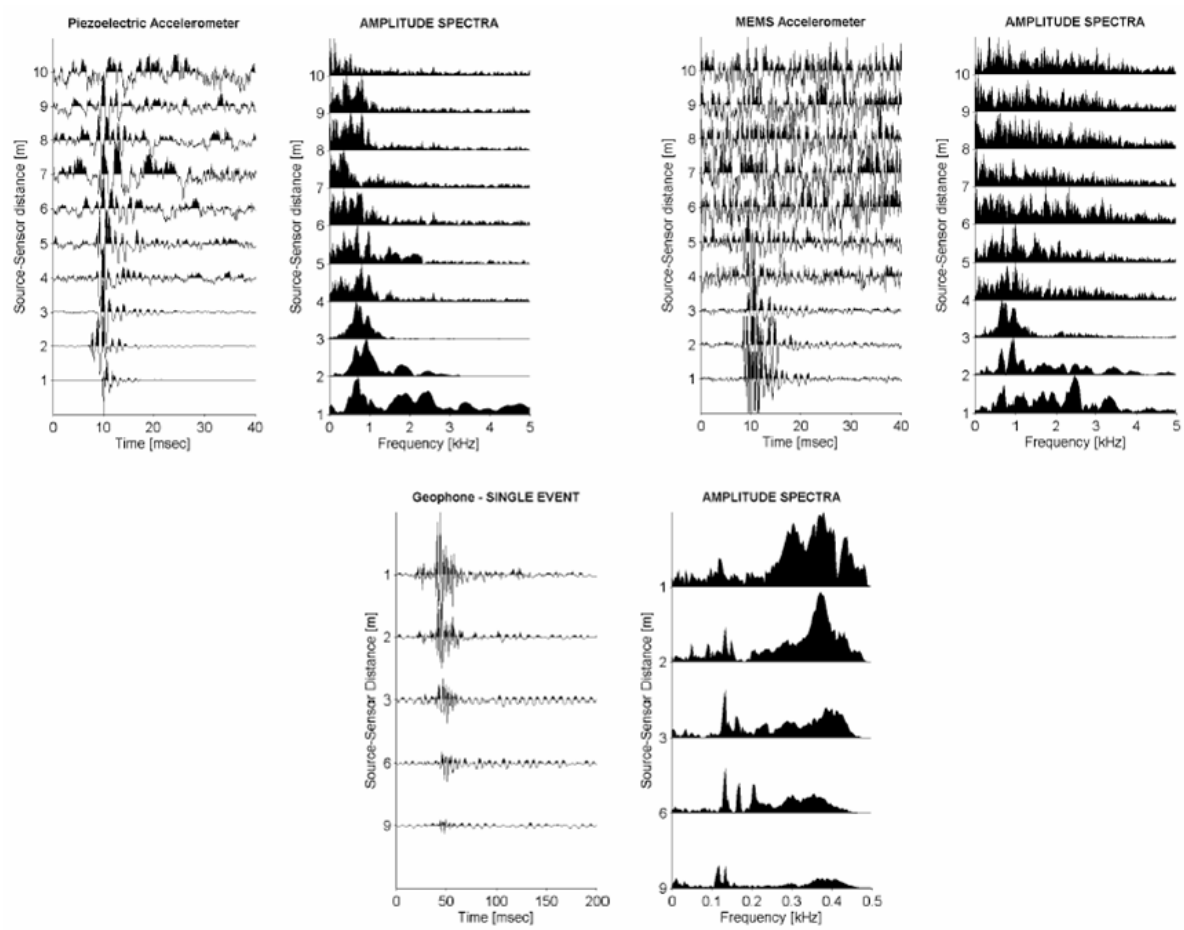

Fig. 11. Top: signals collected departing from the source with piezoelectric (left) and MEMS (right) accelerometers (time and frequency amplitudes normalized to the maximum of each event). Bottom: event collected by the geophone array during the hydraulic jack test (time and frequency amplitudes normalized to the overall maxima).

the field technician using the hammer cannot be considered a perfectly repeatable source, particular attention was paid to this detail. The geophone dataset was again strongly affected by the resonance of the mounting, and though notch filtering was attempted, processed data remained almost insignificant. From piezoelectric and MEMS datasets (Fig. 11) it is quite easy to track higher frequency component attenuation, with the former having an acceptable SNR almost up to a distance of $10 \mathrm{~m}$. MEMS signals are discernable only up to a $3 \mathrm{~m}$ distance; at further distances time histories are fully corrupted by noise and the amplitude spectrum tends to become white. Frequency content above $3 \mathrm{kHz}$ of events collected with MEMS accelerometer at 1 and $2 \mathrm{~m}$ distance has no physical meaning, since it is due to clipping of the events by the A/D converter. Finally, amplitude values collected at an increasing distance from the source by both the geophone array and by the piezoelectric accelerometer were fitted considering the spherical divergence of the wavefront as well as the exponential decay due to absorption. An average value of $2 \mathrm{~dB} / \mathrm{m}$ was found for the attenuation constant, indicating that amplitude values are halved every $3 \mathrm{~m}$.

Our tests confirmed the optimal performance of highpriced piezoelectric accelerometers, while extremely cheap MEMS transducers were affected by drawbacks related to their narrow bandwidth and low sensitivity. Despite their outstanding SNR, geophone datasets were strongly affected by the resonance of the mounting. When dealing with investiga- tions on a more realistic scale, unstable slopes often involve considerable areas to be monitored. Thus, the finest solution may be to deploy low cost broadband MEMS sensors close to active fracture zones, and a sparse network of very sensitive geophones, providing proper mounting strategies are adopted. Obviously, further releases of MEMS accelerometers with higher sensitivity and larger spectral content are strongly encouraged.

\section{Conclusions}

Recent advancements in sensing technologies are improving the capability of understanding rockfall triggering signals. Nevertheless, rockfall forecasting remains a challenging issue. The problem is so complex that none of the currently available sensing technology can give a comprehensive vision of all the active processes which might result in a rockfall event. The reason for that is twofold: a) each process that might reduce the stability of the rock mass yields a signal of a different nature (e.g., geometric deformations, acoustic emissions, etc.) requiring a devoted technique to be detected; b) the magnitude of these signals is often very close to the limit of the instrument's sensitivity. As a result, a proper integration of different technologies appears to be strategic for the design of a reliable monitoring system. In particular, the integration of surface and sub-surface methods may be 
promising to produce an alert system based on multiple and dynamic thresholds which may provide an improvement in early warning systems:

- multiple: for the reason that our final purpose is to link different monitoring systems and to generate some relationship among different physical parameters.

- dynamic: because it may allow the frequency of measurements to be increased, when some detected values were exceeded.

At present, the method with the highest potential for subsurface monitoring is the $\mathrm{AE}$ technique although the optimization of the network design and the definition of proper thresholds still require some field investigation. The results of a small scale test demonstrate that suitable sensors are able to track microseismic activity trends relating to an evolving fracture in terms of both frequency and magnitude of collected data. Nevertheless, elastic signals propagating in unfavourable conditions, as in the presence of fractures and discontinuities affecting the integrity of a rock slope, may be heavily attenuated and distorted before being recorded or may not be recorded at all. Since unstable slopes often involve considerable areas to be monitored, we would like to suggest an $a d$ hoc approach deploying broadband accelerometers close to particularly active zones and sparse network of geophones to collect low frequency signals on a larger scale.

The definition of thresholds remains a challenging task and may be addressed by making use of a probabilistic approach based on diverse assessment and monitoring data. The development of a "site history" in terms of AE counts and location is strongly advisable though.

As far as surface monitoring methods are concerned, several techniques are available and can be properly combined depending on the characteristics of each specific case. Typically, TLS can be used to detect changes in the whole rock surface resulting from mass detachments while it is not capable of measuring deformations induced by forthcoming cracking. On the contrary, total stations feature a higher measurement precision but are limited to a few points. Then, they can be used only for the measurement of global deformations of the rock slope or to control some larger rock blocks. In addition, when the distance to the target is longer than a few dozens of meters the achievable precision becomes inadequate for monitoring purposes. Finally, GB-InSAR sensor seems to be a very promising technique for measuring submillimeter deformations of the rock slope surface. However, some field experiments are still necessary for fine-tune the data acquisition and processing procedure to this specific application and for better modeling of local environmental effects. A last drawback of this technology is that it is still very expensive and requires the installation of cumbersome equipment.
Future developments on this research topic are not only the improvement of single sensing techniques but mainly consist of data integration at signal and achievable information level.

Acknowledgements. This work was partially funded by Politecnico di Milano, within the framework of PROMETEO Project (http://www.prometeo.polimi.it). The authors are grateful to the provincial administration of the city of Lecco for granting access to the test-sites and wish to thank Cristian Galperti who made MEMS sensor datasets available. The comments of two anonymous reviewers helped to improve the quality of the manuscript.

Edited by: A. Volkwein

Reviewed by: three anonymous referees

\section{References}

Abellán, A., Vilaplana, J. M., and Martínez, J.: Application of a long-range Terrestrial Laser Scanner to a detailed rockfall study at Vall de Nuria (Eastern Pyrenees, Spain), Eng. Geol., 88, 136148, 2006.

Abellán, A., Jaboyedoff, M., Oppikofer, T., and Vilaplana, J. M.: Detection of millimetric deformation using a terrestrial laser scanner: experiment and application to a rockfall event, Nat. Hazards Earth Syst. Sci., 9, 365-372, 2009, http://www.nat-hazards-earth-syst-sci.net/9/365/2009/.

Alba, M., Bernardini, G., Giussani, A., Ricci, P. P., Roncoroni, F., Scaioni, M., Valgoi, P., and Zhang, K.: Measurement of Dam Deformations by Terrestrial Interferometric Techniques, The International Archives of the Photogrammetry, Remote Sensing and Spatial Information Sciences, 37(B1), 133-139, online available at: http://www.isprs.org/congresses/beijing2008/ proceedings/tc1.aspx, 2008.

Alba, M., Fregonese, L., Prandi, F., Scaioni, M., and Valgoi, P.: Structural Monitoring of a Large Dam by Terrestrial Laser Scanning, in: The International Archives of the Photogrammetry, Remote Sensing and Spatial Information Sciences, 36(5), Dresden, Germany, 6 pp., unpaginated CDROM, online available at: http://www.isprs.org/commission5/proceedings06/ pages/start.html, 2006.

Alba, M., Longoni, L., Papini, M., Roncoroni, F., and Scaioni, M.: Feasibility and Problems of TLS in Modeling Rock Faces for Hazard Mapping, The International Archives of the Photogrammetry, Remote Sensing and Spatial Information Sciences, 36(3/W19), 156-161, online available at: http://www. commission3.isprs.org/laserscanning2005, 2005.

Alippi, C., Galperti, C., and Zanchetta, M.: Micro acoustic monitoring with MEMS accelerometers: Towards a WSN implementation, Sixth IEEE Conference on Sensors, 966-969, 2007.

Anderson, J. M. and Mikhail, E. M.: Surveying: Theory and Practice, McGraw-Hill Science/Engineering/Math, 1997.

Antonello, G., Casagli, N., Farina, P., Leva, D. D., Nico, G., Sieber, A., and Tarchi D.: Ground-based SAR interferometry for monitoring mass movements, Lanslides, 1(1), 21-28, 2004.

Arosio, D., Longoni, L., Papini, M., Scaioni, M., Zanzi, L., and Roncella, R.: Integrated approach to unstable rock slopes assessment and risk analysis with surface and subsurface non-invasive investigations, Natural Hazards and Earth System Sciences, Nat. Hazards Earth Syst. Sci., submitted, 2009. 
Atkinson, B. K.: Fracture mechanics of rock, Academic press geology series, Academic Press, London, UK, 1991.

Cai, M., Kaiser, P. K., Tasaka, Y., Maejima, T., Morioka, H., and Minami, M.: Generalized crack initiation and crack damage stress thresholds, Int. J. Rock Mech. Min., 41(5), 833-847, 2004.

Corsini, A., Farina, P., Antonello, G., Barbieri, M., Casagli, N, Coren, F., Guerri, L., Ronchetti, F., Sterzai, P., and Tarchi, D.: Space-borne and ground-based SAR interferometry as tools for landslides hazard management in civil protection, Int. J. Remote Sens., 27(12), 2351-2369, 2006.

Crosta, G. B. and Agliardi, F.: Failure Forecast for large rock slides by surface displacement measurements, Can. Geotech. J., 40, 176-191, 2003.

Danisch, L., Chrzanowski, A., Bond, J., and Bazanowski, M.: Fusion of geodetic and MEMs sensors for integrated monitoring and analysis of deformations, in: Proceedings of 13th FIG Symp. on Deformation Measurement and Analysis/4rd IAG Symp. on Geodesy for Geotechnical and Structural Engineering, Lisbon, Portugal, 12-15 May 2008, on CDROM, 10 pp., 2008.

Eberhardt E., Stead D., Stimpson B., and Read, R. S.: Identifying crack initiation and propagation thresholds in brittle rock, Can. Geotech. J., 35, 222-233, 1998.

Faber, K. and Maxwell, P. W.: Geophone spurious frequency: what is it and how does it affect seismic data quality?, Canadian Journal of Exploration Geophysics, 33, 46-54, 1997.

Ferretti, A., Monti Guarnieri, A., Prati, C., Rocca, F., and Massonet, D.: InSAR Principles: Guidelines for SAR Interferometry Processing and Interpretation, ESA Publications, Noordwijk, The Nederlands, 2007.

Ferretti, A., Prati, C., and Rocca, F.: Permanent Scatterers in SAR Interferometry, IEEE T. Geosci. Remote, 39(1), 8-20, 2001.

Gordon, S. J. and Lichti, D. D.: Modeling Terrestrial Laser Scanner Data for Precise Structural Deformation Measurement, J. Surv. Eng.,133(2), 72-80, 2007.

Green, A. G., Maurer, H., Spillmann, T., Heincke, B., and Willenberg, H.: High-resolution geophysical techniques for improving hazard assessments of unstable rock slopes, The Leading Edge, 25, 311-316, 2006.

Griffith, A. A.: The phenomenon of rupture and flow in solids, Philos. T. Roy. Soc. A, 221, 163-198, 1920.

Hardy Jr., H. R.: Acoustic emission/Microseismic activity. Principles, techniques and geotechnical applications, Vol. 1, A. A. Balkema Publishers, 292 pp., 2003.

Henk, K.: High-End Total Stations, GIM International, 6, 2007.

Hofmann-Wellenhof, B., Lichtenegger, H., and Wasle, E.: GNSS Global Navigation Satellite Systems: GPS, GLONASS, Galileo and More, Springer, New York, USA, 516 pp., 2008.

Lambrou, E. and Pantazis, G.: A new geodetic methodology for the accurate Documentation and Monitoring of inaccessible surfaces, Proceedings of 12th FIG Symp. on Deformation Measurement and Analysis/3rd IAG Symp. on Geodesy for Geotechnical and Structural Engineering, Baden, Austria, 22-24 May 2006, on CDROM, 8 pp., 2006.

Leva, D., Nico, G., Tarchi, D., Fortuny-Guasch, J., and Sieber, A. J.: Temporal Analysis of a Landslide by Means of a Ground-Based SAR Interferometer, IEEE T. Geosci. Remote, 41(4), 745-752, 2003.

Lindenberg, R. and Pfeifer, N.: A Statistical Deformation Analysis of Two Epochs of Terrestrial Laser Data of a Lock, in: Pro- ceedings of Optical 3-D Measurement Techniques VII, Vienna, Austria, 18-22 September 2005, Vol. 2, 61-70, 2005.

Lingua, A., Piatti, D., and Rinaudo, F.: Remote monitoring of a landslide using an integration of GB-InSAR and lidar techniques. The International Archives of the Photogrammetry, Remote Sensing and Spatial Information Sciences, 37(B1), 133-139, 361-366, online available at: http://www.isprs.org/congresses/ beijing2008/proceedings/tc1.aspx, 2008.

Lockner, D. A.: Rock failure. Rock physics and phase relations, rock physics and phase relations, Washington, DC, American Geophysical Union, 127-147, 1995.

Martin, C. D., Christiansson, R., and Soderth, J.: Rock stability considerations for siting and costructing a KBS-3 repository based on Experience from Aspo HRL, AECL's URL, Tunneling and Mining, 2001.

Monserrat, O. and Crosetto, M.: Deformation measurement using terrestrial laser scanning data and least squares 3D surface matching, ISPRS J Photogramm., 63(1), 142-154, 2008.

Obert, L. and Duvall, W. I.: Use of subaudible noises for the prediction of rock burst. Part II, Report of Investigations 3654, US Bureau of Mines, 1942.

PermadataRoc: online available at: http://www. fondazionemontagnasicura.org/multimedia/permadataroc/ start_ita.htm, last access: 28 January 2009.

Pfeifer, N. and Lichti, D.: Terrestrial Laser Scanning, GIMInternational, 18(12), 50-53, 2004

Reiterer, A., Lehmann, M., Miljanovic, M., Ali, H., Paar, G., Egly, U., Eiter, T., and Kahmen, H.: Deformation monitoring using a new kind of optical 3D measurement system: components and perspectives, in: Proceedings of 13th FIG Symp. on Deformation Measurement and Analysis/4th IAG Symp. on Geodesy for Geotechnical and Structural Engineering, Lisbon, Portugal, 12 15 May 2008, on CDROM, 10 pp., 2008.

Riegl: online available at: http://www.riegl.com/products/ terrestrial-scanning/, accessed: 28 January 2009.

Roncella, R. and Forlani, G.: Extraction of planar patches from point clouds to retrieve dip and dip direction of rock discontinuities, The International Archives of the Photogrammetry, Remote Sensing and Spatial Information Sciences, 36(3/W19), 162-167, online available at: http://www.commission3.isprs.org/ laserscanning2005, 2005.

Rose, N. D. and Hungr, O.: Forecasting potential rock slope failure in open pit mines using the inverse-velocity method, Rock Mechanics and Mining Sciences, 44, 308-320, 2007.

Rowell G. A. and Yoder L. P.: The effect of geophone emplacement on the observed frequency content of microseismic signals, Proceedings, Third Conference on Acoustic Emission/Microseismic Activity in Geologic Structures and Materials, The Pennsylvania State University, October 1981, Trans. Tech. Publications, Clausthal-Zellerfeld, Germany, 707-727, 1984.

Saleh, B. and Al-Bayari, O.: Geodetic monitoring of a landslide using conventional surveys and GPS techniques, Surv. Rev., 39(305), 252-260, 2007.

Spillmann T.: Borehole radar experiments and microseismic monitoring of the unstable Randa rockslide (Switzerland). $\mathrm{PhD}$ dissertation no. 16866, Swiss Federal Institute of Technology, Zurich, Switzerland, 205 pp., 2007.

Spillmann, T., Maurer H., Green A. G., Heincke B., Willenberg H., and Husen S.: Microseismic investigation of an unstable 
mountain slope in the Swiss Alps, J. Geophy. Res., 112, B07301, doi:10.1029/2006JB004723, 2007.

Stimson, G. W.: Introduction to Airborne Radar, Sci. Tech. Publishing Inc., USA, 576 pp., 1998.

Sullivan, T. D.: Understanding pit slope movements, in Proc. of Geotechnical Instrumentation and Monitoring in Open Pit and Underground Mining, Kalgoorlie, Western Australia, June 1993, 435-445, 1993.

Szwedzicki, T.: Rock mass behaviour prior to failure, Int. J. Rock Mech. Min., 40, 573-584, doi:10.1016/S1365-1609(03)00023, 2003.

Tarchi, D., Casagli, N., Fanti, R., Leva, D. D., Luzi, G., Pasuto, A., Pieraccini, M., and Silvano, S.: Landslide monitoring by using groud-based SAR interferometry: an example of application to the Tessina landslide in Italy, Eng. Geol., 68(1), 15-30, 2003.

Tarchi, D., Rudolf, H., Luzi, G., Chiarantini, L., Coppo, P., and Sieberg, A. J.: SAR interferometry for structural changes detection: a demonstration test on a dam, in: Proceedings of IGARSS 99, 28 June-2 July 1999, Hamburg, Germany, Vol. 3, 15221524, 1999.
Tsakiri, M., Lichti, D., and Pfeifer, N.: Terrestrial Laser Scanning for deformation monitoring. Proceedings of 12th FIG Symp. on Deformation Measurement and Analysis/3rd IAG Symp. on Geodesy for Geotechnical and Structural Engineering, Baden, Austria, 22-24 May 2006, on CDROM, 10 pp., 2006.

Werner, C., Strozzi., T., Wiesmann, A., and Wegmüller, U.: GAMMA's portable radar interferometer, in: Proceedings of 13th FIG Symp. on Deformation Measurement and Analysis/4th IAG Symp. on Geodesy for Geotechnical and Structural Engineering, Lisbon, Portugal, 12-15 May 2008, on CDROM, 10 pp., 2008.

Zhang, Z. X.: An empirical relation between mode I fracture toughness and the tensile strength of rock, Int. J. Rock Mech. Min.,39(3), 401-406, doi:10.1016/S13651609(02)00032-1, 2002. 